\title{
LOCATION OF CAVITIES WITH GEOPHYSICAL METHODS: AN EXAMPLE OF COMBINATION OF SEISMIC REFLECTION AND DIPOLE GEOELECTRICS IN THE PHLEGREAN FIELDS (SOUTHERN ITALY)
}

\author{
Giovanni Bais, Pier Paolo G. Bruno, Eugenio Carrara, Giovanni Florio, \\ Valeria Paoletti, Nicola Roberti and Antonio Rapolla
}

Dipartimento di Geofisica e Vulcanologia, Universitá Federico II, Napoli, Italia

\begin{abstract}
A shallow seismic reflection and a dipole geoelectric surveys were carried out at one site located in the Phlegrean Fields, a volcanic area near Naples (Italy). The target is constituted by a railway tunnel excavated in the "Neapolitan Yellow Tuff", a compact volcanic formation very common in the area. The test has an important practical application, in terms of reduction of the risk associated with the presence of many unknown cavities, dug in the past centuries into the tuff formation to extract material for building. In order to predict the seismic and electric response of the ground-cavity system, 2D syn-thetic wave propagation seismograms and 2D models of the electric response of the ground were produced.
\end{abstract}

As a result of the seismic processing, it was found a break into the reflection from the top of tuff in correspondence of the tunnel. Some diffracted energy also detected further evidence of the presence of the tunnel on the seismic section. Nevertheless other disturbances are pre-sent on the seismic section at different locations. The electric survey consisted in a number profiles, transversal to the tunnel, carried out with dipole-dipole electrodic arrangement with different electrodic spacing. The survey showed that the electric resistivity distributed in the studied area is rather complex and therefore the anomaly due to the cavity is of little amplitude.

Both seismic and electric data show, in addition to the anomaly due to the presence of the tunnel, other anomalous areas. This fact in general could lead to difficulties in cavity loca-tion when a single method is used. In our case, the combined interpretation of the electric and seismic data allowed to identify the anomaly due to the tunnel and to separate it from the others. 
